\title{
Environmental Sanitation Planning: Feasibility of the CLUES Framework in a Malawian Small Town
}

\author{
Wema Meranda Mtika ${ }^{1}$ and Elizabeth Tilley ${ }^{1,2 *}$ \\ ${ }^{1}$ WASHTED Center, The University of Malawi-The Polytechnic, Blantyre, Malawi, ${ }^{2}$ SANDEC: Department of Sanitation, Water \\ and Solid Waste for Development, EAWAG: Swiss Federal Institute of Aquatic Science and Technology, Duebendorf, \\ Switzerland
}

\section{OPEN ACCESS}

Edited by: Juliet Willetts,

University of Technology Sydney, Australia

Reviewed by:

Vhahangwele Masindi,

Council for Scientific and Industrial

Research (CSIR), South Africa

Spyros Foteinis,

Council for Scientific and Industrial

Research (CSIR), South Africa

Jennifer R. McConville,

Swedish University of Agricultural

Sciences, Sweden

*Correspondence:

Elizabeth Tilley

elizabeth.tilley@eawag.ch

Specialty section:

This article was submitted to Water and Wastewater Management,

a section of the journal

Frontiers in Environmental Science

Received: 30 June 2019 Accepted: 17 December 2019

Published: 29 January 2020

Citation:

Mtika WM and Tilley E (2020)

Environmental Sanitation Planning: Feasibility of the CLUES Framework in

a Malawian Small Town.

Front. Environ. Sci. 7:204.

doi: 10.3389/fenvs.2019.00204
Small towns are growing in size and number, but compared to the big cities that fuel economies, or rural areas that feed nations, small towns are generally less prioritized by governments and donors, both because they appear less immediately troublesome and because they defy easy classification. As such, growth has largely been unplanned for and remains unregulated, which means that responsible governments lack the commensurate tax base and political might to plan for and aquire the services they need to handle the changes that they face. For exactly these reasons, the Community-Led Urban Environmental Sanitation (CLUES) tool was developed to assist small towns with the planning and implementation of environmental sanitation infrastructure and services but we found no documented cases of it being used or evaluated. The goals of this work were to first, document the information obtained from the CLUES process as a case study for the condition of environmental sanitation in a small town in Malawi; and secondly, to evaluate the technical, political, and financial feasibility of the CLUES manual in a Malawian context. As facilitators, we guided the community and government through each of the 7 CLUES steps over the course of 2 years to understand the actual demands of the guidelines from the perspective of the user. Once the process was completed, we were able to critically reflect on our stated objectives and present those results here. The results of the process revealed that water quality was good (no measured $E$. coli at 45 water points) as was access to a sanitation facility, though water quantity was insufficient and fecal sludge management and solid waste collection required Council attention. However, because baseline data were outdated or non-existent, the data collection activities required to determine the status consumed unexpected amounts of time, and the results were, because of internal movement and politics, difficult to disseminate and leverage. Most importantly, stakeholder participation was limited and relied on participation and transportation payments, which have become a permanent feature of community development in Malawi. Following the CLUES process was expensive, time consuming and politically fraught; it is unlikely that any small town in Malawi would be able to follow the process as outlined. A simplified version, conducted by an in-house planning department should focus on identifying gaps, needs, and priorities, as a way of not only addressing environmental sanitation issues, but as a way to kick-start better data collection and management that can underscore long-term planning activities.

Keywords: planning, small-town, sanitation, rural, urban, urbanization, Malawi, Africa 


\section{INTRODUCTION}

Urbanization is occurring rapidly; it is estimated that 60 million people move to urban areas annually (CWIS, 2018) and most of the growth is in informal settlements and slums (Water Aid, 2016). Although the population in Africa and Asia is predominantly rural (50 and 58\%, respectively), more people will be living in urban areas by 2030 (Ikwuyatum, 2016). It is estimated that globally, city populations will increase by 50\%, from 4 to 6 billion between 2016 and 2045 (Tayler, 2018). The rural-urban shift has brought increased economic growth (Ikwuyatum, 2016) but employment opportunities are increasingly difficult to come across as is land for housing or urban agriculture. With an increasing number of residents, cities struggle to provide public services, especially when the tax base does not grow accordingly (Awumbila, 2017). However, urbanization does not just affect big cities: knowing that many cities have reached their capacity to take newcomers, young migrants are diversifying their destinations and as a result, small towns are expected to double in size and number within 15 years, and double again within 30 years (Caplan and Harvey, 2010).

Small towns are broadly defined as small urban settlements or secondary towns (Sandec-Eawag, 2017). There is no universal definition for small towns because the population threshold used in different countries is not consistent (Roberts, 2014) but generally ranges between 1,000 and 50,000 inhabitants (Owusu, 2005; Wessels, 2012; Roberts, 2014). Alternative definitions frame small towns from an economic-development perspective: "small district hubs that have potential to become economic drivers of activity and services to rural areas" (Thomas and Alvestegui, 2015). Regardless of definition, central governments generally prioritize small towns less than large urban centers, as they have fewer constituents, and therefore less political power. On the other hand, and unlike growing cities, they are opportunities to demonstrate tangible change, as they have not developed beyond the point at which major infrastructure or planning changes are no longer possible.

Despite global efforts to increase the availability of improved water and sanitation for all, only $24 \%$ of the sub-Saharan population has access to safely managed water, i.e., individuals have a water facility accessible on the premises, water is available when needed (at least $12 \mathrm{~h} /$ day), and water supplied is free from contamination, i.e., fecal and chemical contamination (World Health Organization and UNICEF, 2017). Fecally-contaminated water is often associated with diarrhea, which is especially dangerous for children and those with weakened immune systems (Nguyen et al., 2017). Similarly for sanitation, $72 \%$ of the sub-Saharan population lacks even basic sanitation (World Health Organization and UNICEF, 2017), though access is not uniform between rural (26\%) urban (34\%) areas (Hutton and Varughese, 2016). During the 1980s most Water, Sanitation and Hygiene (WASH) services were focused on rural areas, and then in the 1990s, the focus shifted to urban areas, where small towns started to received investments in piped water supply infrastructure. However, funding for operation, maintenance, and the eventual expansion did not follow (Mugabi and Njiru, 2005).
WASH services in small towns are largely neglected by government officials due to a lack of capacity, weak institutional frameworks defined by unclear responsibilities among stakeholders, inadequate financial resources, and a lack of feasible sanitation solutions (Thomas and Alvestegui, 2015). Specifically, most technology-driven solutions are usually not feasible or affordable due to high poverty rates among dwellers and a small tax base collected by local authorities (Thomas and Alvestegui, 2015; Humphreys et al., 2018). Despite the evidence that poor people are willing to pay for improved water and sanitation services, most continue to use unregulated private services since system managers are often unable to recover the costs related to providing new or rehabilitated systems (Mugabi and Njiru, 2005). Further complicating provision is the fact that small towns are typically unplanned, and have mixed urban and rural attributes (Mugabi and Njiru, 2005). For example, centralized water and wastewater infrastructure is normally managed by city councils and/or utilities in cities, with little responsibility for the customer, while in rural areas, sanitation (usually pit latrines) are managed by the household. Small towns are increasingly required to provide city-like services, but to a population with rural-like infrastructure, making management difficult, and potentially fragmented. Furthermore, the incomplete transfer of power to local organizations, a lack of transparency and accountability, and encroachment of power by the local elite negatively affect the equitable distribution of water resources (Richards and Syallow, 2018).

Planning has been described as "deciding between various options for the future and then acting to see that they are implemented" (Kvarnström and McConville, 2007). More specifically, Municipal Sanitation Plans, Water and Sanitation Strategy Plans, or City Sanitation (Master) Plans (CSPs) assist with citywide sanitation development by incorporating visions, missions, and goals and strategies (Wafler, 2018). The challenge however, is that funding for sanitation plans is rarely incorporated into national budgets, and as small towns lack the tax base to self-support these activities (Water Aid, 2016). Because there is often an overlap in several departments with different vested interests, coordination becomes cumbersome (Water Aid, 2016). It is exactly for this reason that methodical, clear planning approaches are required to help planners jointly identify problems, targets, and timelines.

Various sanitation planning frameworks have been developed to address the needs of different users in the urban world: Open Planning of Sanitation Systems, which was recommended by the EcoSanRes Programme in 2004 (Kvarnström and McConville, 2007); the Household-Centered Environmental Sanitation (HCES), developed by the Swiss Federal Institute of Aquatic Science and Technology (Eawag) in 2005; Sanitation 21, developed by the International Water Association (IWA) in 2006 (Kvarnström and McConville, 2007); and the Strategic Sanitation Approach (Wright, 1997). It is difficult to adequately assess the effectiveness of these tools, or their relative applicability to small towns, given the near lack of documented case studies. Peal et al. (2010) assessed the state of documented planning cases, and we have found no additional information since. 


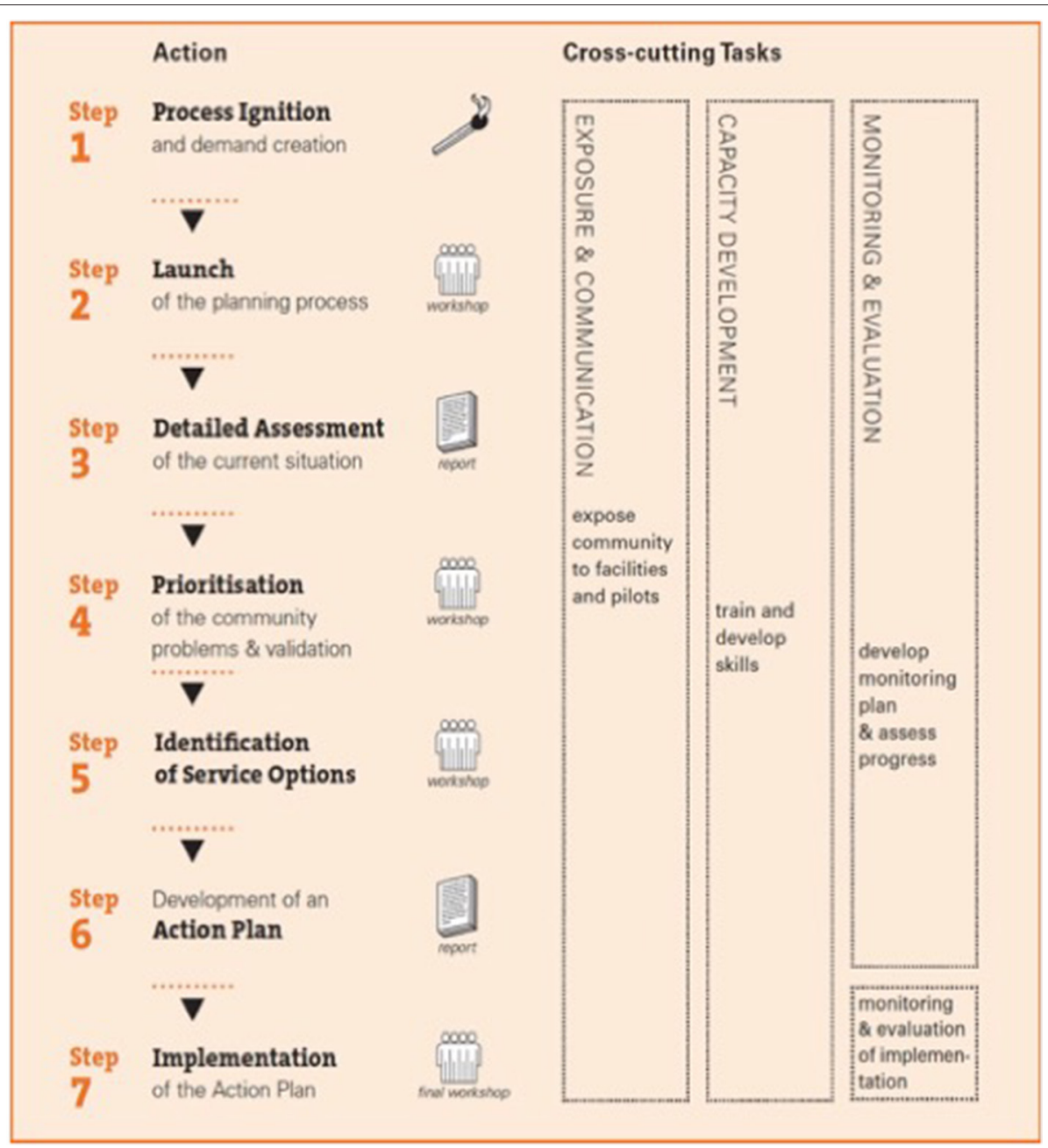

FIGURE 1 | The 7 planning steps of CLUES (Source: Lüthi et al., 2011).

Uniquely, the Community Led Urban Environmental Sanitation (CLUES) approach was developed specifically for the planning and implementation of environmental sanitation infrastructure and services in low-income small towns (Lüthi et al., 2011). Figure 1 summarizes the 7 planning steps of CLUES.

Along with studies underway in Nepal and Bolivia this is one of the first cases of a sanitation planning approach for a small town that we know to be documented.

In Malawi there are 4 city councils: one for each of the major cities in the country (Lilongwe, Blantyre, Zomba, and Mzuzu), and two municipal councils for what could be called "small towns" (Luchenza and Kasungu) (Luchenza City Council, 2013; OECD, 2016). Luchenza municipality is in the southern region of Malawi and shares boundaries with Thyolo district to the west and south, Mulanje district to the east and Chiradzulu to the north (Luchenza City Council, 2013). In 2019, Luchenza municipality had an approximate total population of 12,600 (National Statistics Office, 2019).

Inadequate access to safe water, sanitation and practical hygiene services are some of the key challenges faced by, and identified previously by the Luchenza Council. All wards have mixed housing densities which is attributed to a failure to adhere to the housing plan, control of land by chiefs, laxity in development control, and poor staffing levels (Luchenza City Council, 2013).

Using Luchenza as a case study, the goals of this work were to first, document the information obtained from the CLUES process as a case study for the condition of environmental sanitation in a small town in Malawi; and secondly, to evaluate the technical, political, and financial feasibility of the CLUES manual in a Malawian context.

\section{METHODS}

\section{Setting}

The 2-year study was conducted in Luchenza municipality in southern Malawi (Figure 2) and covered all 8 wards of Luchenza: Lolo, Thundu, Sambagalu, Kapiri, Luchenza, Namadzi, Mapanga, and Namisonga. 


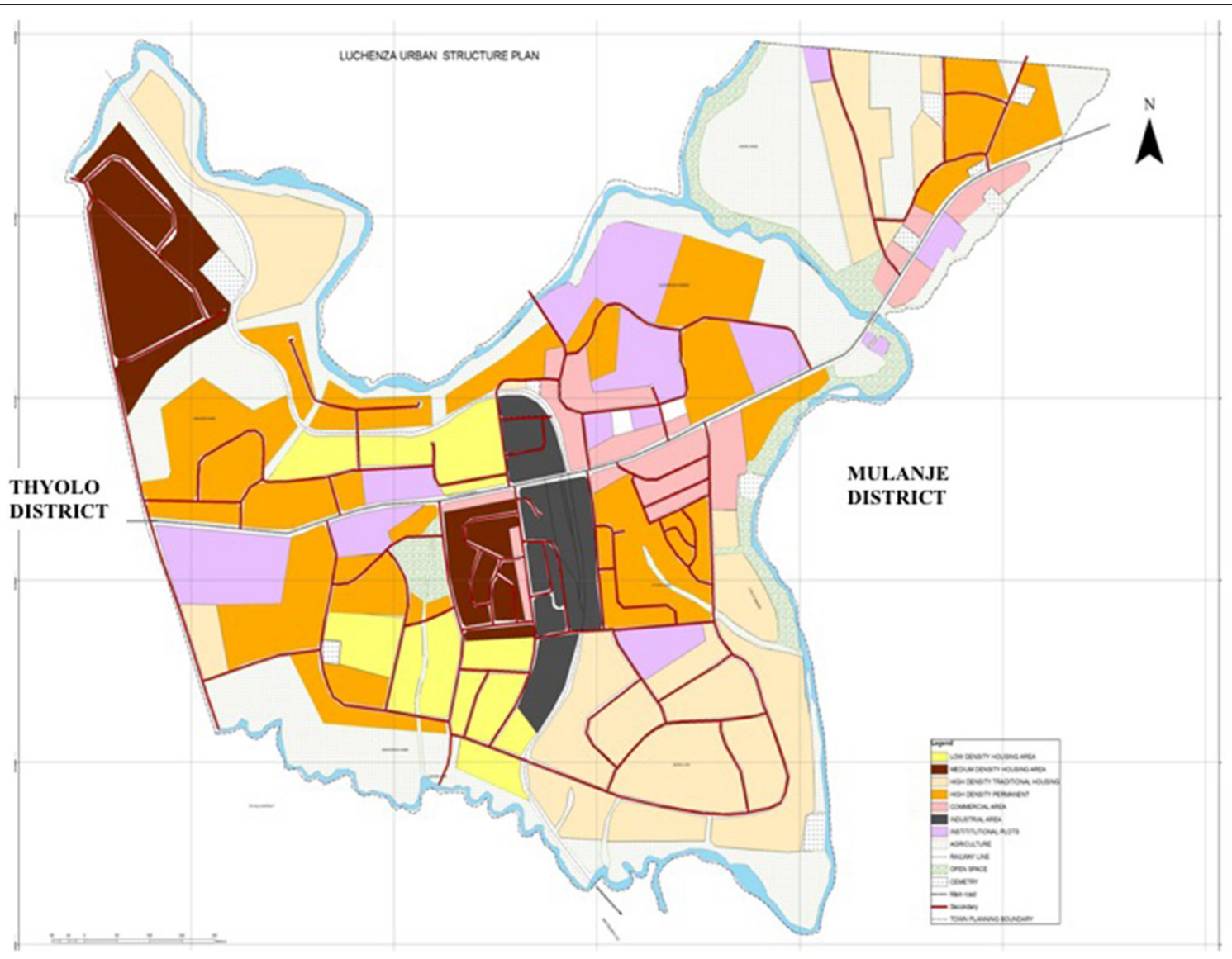

FIGURE 2 | Map of Luchenza.

The Luchenza Municipal Council is a statutory body set up under the Local Government Act 1998 Cap. 22:02. The local council is mandated to pass by-laws, mobilize resources for development, maintain peace and security, and promote infrastructure, economic, and social development through the formulation, approval and implementation of the programs and projects. The Chief Executive Officer (CEO) is the head of the Council and is assisted by directors of council departments. The Urban Executive Committee (UEC) is the technical advisory body to the Municipal Council. It is composed of all government line ministries, statutory corporations and non-governmental organizations working in the district (Luchenza City Council, 2013).

Traditional leaders, who inherit power through lineage, still retain significant influence on the politics in Malawi despite the fact that they exist outside of the democratic system. The traditional leader hierarchy (from highest to lowest power): Traditional Authority Group Village Heads (GVHs), Village Heads (VHs), and village chiefs. Each of the GVHs has a councilor (Luchenza City Council, 2013). The Council structure is presented in Figure 3.

The town was selected based on its size, population growth, typically complex political structure, and expressed interest on the part of the Council.

\section{CLUES Participants}

All environmental sanitation stakeholders that we could identify were included in the CLUES process: community members, municipal council departments, municipal cleaners, traditional leaders, councilors, ward committees, neighborhood committees, Community Based Organizations (CBOs), and business owners. For the data collection in Step 3 (elaborated below), we randomly selected 280 households ( 35 households/ward). The indepth interviews were administered to the Director of Health, the Chair of Health and Environment, 2 municipal cleaners, 1 water point committee representative, and 1 public toilet committee representative. The Director of Health is responsible for overseeing all health and sanitation issues in Luchenza e.g., inspecting food premises for expired goods. Water point committees in Luchenza are responsible for collecting water fees from users, and managing the city-run public toilets.

\section{CLUES Implementation}

The CLUES process is comprised of 7 planning steps and is summarized in Figure 1.

\section{Steps 1 and 2}

Though we attempted to follow the process and written directions as closely as possible during the implementation some 


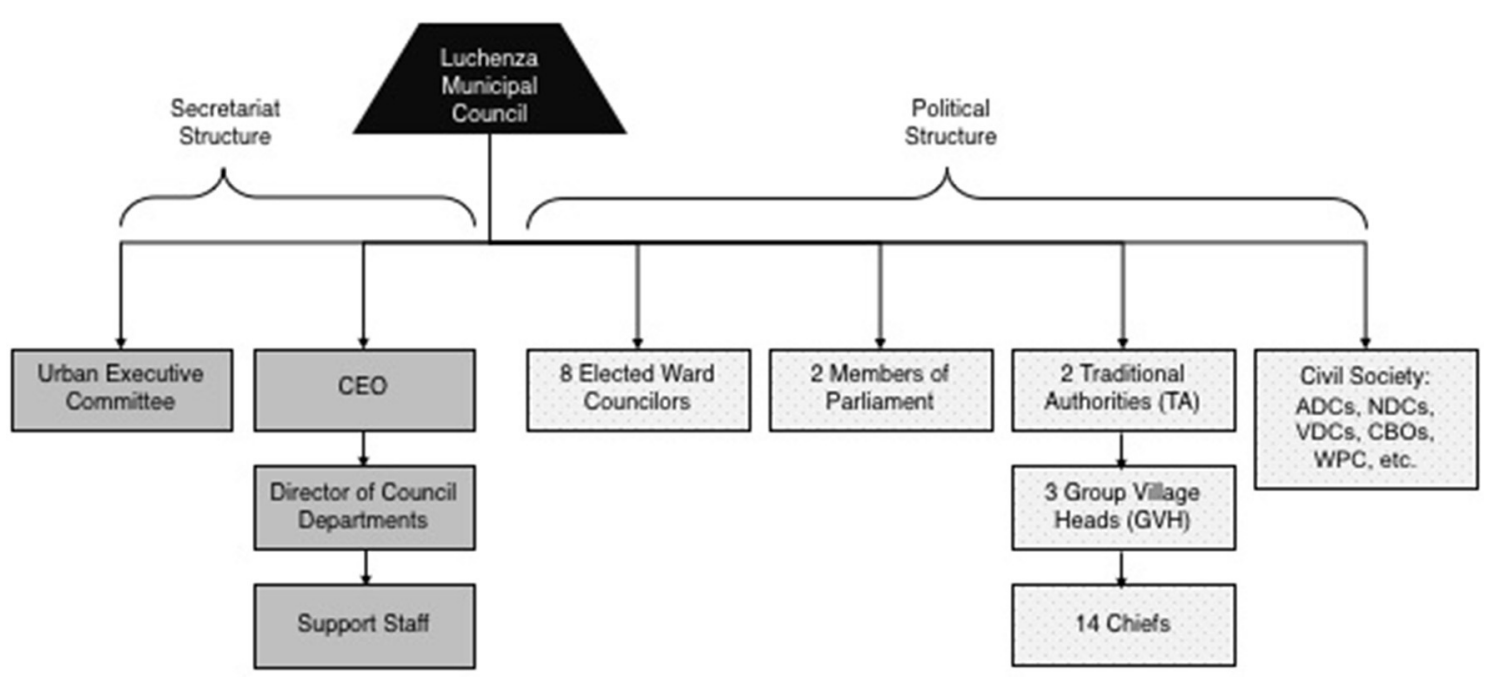

FIGURE 3 | Luchenza Council structure.

changes were made. The first and second planning steps ("Process ignition and demand creation" and "Launch of the planning process," respectively) were merged as the outcomes were deemed to be relatively similar (informing and exciting the community), and as a way to save money on workshops, especially early in the process. In this fused step, environmental sanitation stakeholders were identified using a "snow-balling approach" starting from the council. The main focus was to identify the stakeholders, understand the type of work they were doing with regard to environmental sanitation, and to identify some of the challenges they faced during their work. We met with all department heads through informal meetings and then started going further into communities to identify community stakeholders. Apart from department heads, we met the supervisor for municipal cleaners, 5 CBOs, 2 builders (contractors), 1 plumber, and 6 residents who helped us identify more stakeholders.

Once identified, participants (66) were invited to attend a launching workshop which had 3 main activities: a mapping exercise, a tour around the municipality to supplement the mapping exercise, and a capacity building tour at a children's entrepreneurial training village, called Green Malata. The mapping exercise was held to understand the environmental sanitation situation in Luchenza and to give participants a chance to highlight and explain the challenges and problematic areas in their community. Participants were also asked to place stickers on a map to identify "sanitation hot-spots" e.g., broken water points or open defecation prone areas. Afterwards, all participants visited Luchenza's dump site and a road used for open defecation (commonly called "pa umve" to mean "unhygienic"). The aim of visiting these two sites was to make people aware of their existence and location, and also to identify, as a group, poor practices, causes, effects, and ultimately, possible solutions. The aim of visiting Green Malata was to show participants improved methods of solid waste management: paper recycling, composting, and anaerobic digestion (biogas production).

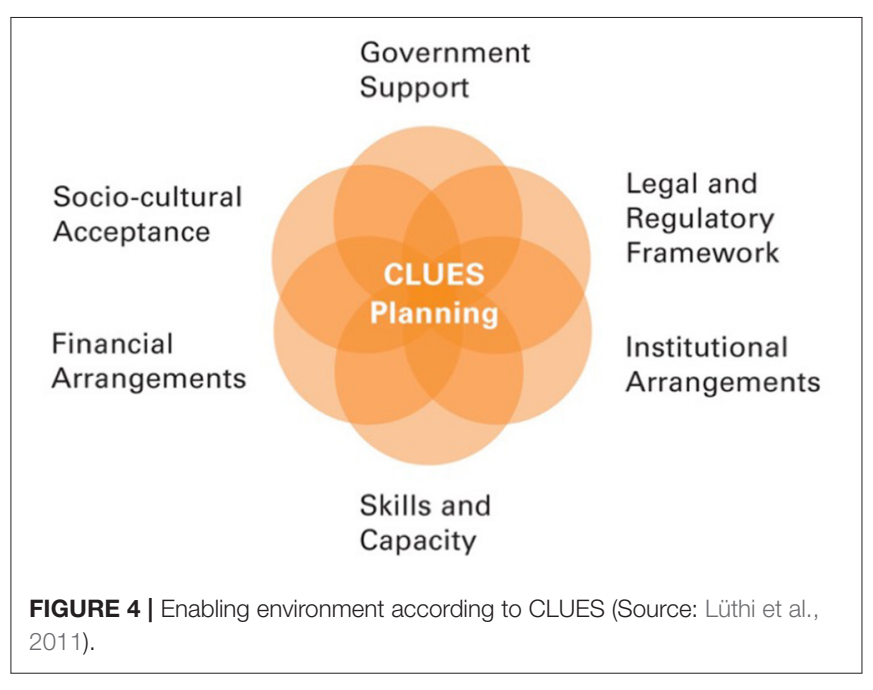

After the launching workshop, we conducted a comprehensive literature analysis/assessment of the enabling environment and the output of this exercise was a status assessment report for Luchenza. The enabling environment is a set of interrelated conditions that impact the capacity of actors to engage in development processes in a sustained and effective manner (Thindwa, 2001). In the CLUES framework, aspects of the enabling environment are government support, legal and regulatory framework, institutional arrangements, skills and capacity, financial arrangements, and socio-cultural arrangements. Figure 4 displays aspects of the enabling environment in the CLUES framework.

The enabling environment for Luchenza was assessed using documents such as by-laws, the Local Government Act, the Public Health Act, and a report on the socio-economic profile of Luchenza. The analysis included information from 
initial project exercises such as the launching workshop and stakeholder meetings.

The assessment of the enabling environment was disseminated among stakeholders. Eight stakeholder representatives received the status assessment report (output of the assessment of the enabling environment) but no specific feedback about the contents of the document was given in return.

\section{Step 3}

The third planning step ("Detailed assessment of the current situation") involved a detailed assessment of the current environmental situation using a cross-sectional, descriptive study which involved a mapping exercise of public water points and public toilets, microbiological water tests at public water points, a household survey, and key informant interviews.

Data from the household survey and mapping exercises were collected electronically using "Kobo Collect" (http://www. kobotoolbox.org). A questionnaire covering the aspects of water supply, stormwater and graywater, sanitation, and solid waste was used to collect data from household respondents to examine current households' practices and performance in environmental sanitation and to determine the factors that contribute to poor environmental sanitation practices in Luchenza. We initially pilot-tested 20 households for validity and the pilot respondents were not included in the main sample.

Open questions were used to collect qualitative data from key informants during interviews to obtain an in-depth understanding of the current service levels.

To determine microbiological water quality, water samples were collected at 45 public water points. The samples were immediately placed in cooler boxes and transported to a laboratory at Chonde Health Centre in Mulanje (the closest laboratory space). Upon arrival at the lab, the water samples were immediately refrigerated and analyzed as rapidly as possible, within $6 \mathrm{~h}$. The samples were analyzed for total coliforms (TC) and Escherichia coli (EC) in colony-forming units using a membrane filtration method. The bags that were used to collect water samples were aseptically opened using a flame-treated pair of scissors. A $100 \mathrm{ml}$ water sample was filtered through a $0.45 \mu \mathrm{m}$ Millipore membrane using a Delaqua filter device. The filters were then placed on Hyserve Compact Dry Plates and incubated at 37 degrees Celsius for $24 \mathrm{~h}$. Thereafter, any colonies formed were counted in colony forming units per $100 \mathrm{ml}$.

\section{Step 4}

Stakeholders in Step 4 ("Prioritization and validation") identified and prioritized environmental sanitation problems through a participatory workshop where the outcomes from planning Step 3 were validated (authenticated). In addition, participants prioritized environmental sanitation problems in Luchenza through a pocket voting exercise, i.e., individuals anonymously ranked their priorities by allocating their votes into different "pockets" (water, sanitation, solid waste, graywater, stormwater).

\section{Steps 5 and 6}

Planning Steps 5 and 6 ("Identification of service options"; "Development of an action plan") were also merged because the outcomes were complementary, i.e., putting together an action plan report, and a comprehensive outline of the service options that were recommended to Luchenza municipality.

\section{Data Analysis}

Workshop and meeting minutes were recorded throughout the steps and were compiled in reports and disseminated to all stakeholder representatives, $\sim 90$ people.

All quantitative data were analyzed using Stata Software Version 11. The raw data from the in-depth interviews and community workshops were analyzed qualitatively. The data were translated into English and transcribed. The written transcripts were grouped into themes and significant statements for each theme were identified and triangulated into the quantitative data to give in-depth analysis.

\section{CLUES Assessment}

The secondary goal of implementing the CLUES process (the first goal being the development of a comprehensive environmental sanitation plan) was to critically assess the financial, technical, and social feasibility of the CLUES process, using Luchenza as our case study.

The financial feasibility was assessed by compiling all nonsalary costs for the project over its duration. Salary costs were not included as salaries for the two researchers were not dedicated exclusively to this project and we hesitate to estimate what fraction of time was dedicated to this work. More importantly, the salaries would not be representative of the hopefully, local government leader, who would be responsible for leading this type of process in the future.

The technical feasibility was based on our own experiences of reading, understanding, following, and ultimately implementing the CLUES guidelines without any outside guidance. The technical feasibility also included an assessment of the logistics and practical challenges to conducting each CLUES step. We compiled much of this information from our internal and public reports that summarized the challenges, delays and reasons throughout the process.

The social feasibility assessment was based on the continuous feedback we received from participants during the process, the feedback given at the final hand-over meeting to the Council, and our own reflections after the 2 year process was complete.

\section{Ethical Practice}

Before launching, permission to conduct the study was sought from the Luchenza Municipal Council and the Thyolo District Health Officer (DHO). The research team met with and proposed the idea to the mayor, the Chief Executive officer (CEO), and the director of administration and they not only agreed to participate in the research, but to host the main researcher at the council office and provide an office space.

We obtained ethical consent (approval 1724) from the National Health Sciences and Research Committee (NHSRC) and permission to conduct the study was obtained from the Luchenza Municipal Council and Thyolo District Health Office. Furthermore, permission to undertake laboratory microbiological water tests at Chonde Health Centre was 
obtained from the health centre itself and from Mulanje District Health Office. Lastly, we obtained informed consent from all participating subjects.

\section{RESULTS AND DISCUSSION CLUES Process \\ Steps 1 and 2}

The CLUES process revealed that increased access to improved environmental sanitation services was recognized by the government as important for socio-economic development. However, funding for implementing environmental sanitation activities was inadequate (effectively absent). In other words, the politicians believed in, or at least professed to the importance of improvements, but were unable or unwilling to budget for them.

In terms of the legal and regulatory framework, laws for governing environmental sanitation services were present. However, most Acts were outdated and laws only focused on the elimination of open defecation and basic solid waste management. The most used regulation for health and environment (Public Health Act), had not been updated since the 1960s, when it was created. Furthermore, fecal sludge disposal laws were not indicated/specified in any of the Acts or by-laws reviewed; the responsibility for by-law enforcement was not clearly specified. However, the absence of regulations which mandate exclusively water-based technologies (i.e., septic tanks and/or sewers), represented a window of opportunity for appropriate solutions, and potentially even locally-designed policy.

Luchenza municipality had a clear administrative structure. Both the political and secretariat structures were functional. There was a history of CBOs working together with the council to improve and promote environmental sanitation. For instance, stakeholders reported that the CBOs, Health Surveillance Assistants (HSAs), and Ward Development Committee (WDC) members carried out inspections to check if households had functional or sufficient sanitary facilities but reported that there was a lack of collaboration among different sectors and departments. Conversely, private sector involvement was minimal. The private sector is small, not industrial and largely family run (small shops, repairs and mechanics, agriculture, etc.). Given that most businesses operated with one or two employees, the economic benefit of civil participation was likely insufficient compared to the income generated with a full staff. Not having any private sector representation was a clear detriment to the development of Luchenza given the potential financial contributions, regardless of how small, that could be obtained.

Local knowledge and technical skills in managing environmental sanitation services were found to be lacking especially for solid waste and fecal sludge management. Most people were knowledgeable about sanitation issues, such as latrine construction. However, it was evident that they were not able to afford durable construction materials hence most latrines collapsed in rainy seasons or during floods.

Printed information for the financial status of the municipality was available for previous years, but had not been compiled for recent ones. Additionally, there was no information on how much funding was allocated to environmental sanitation. The lack of money to fund sanitation services was in part due to the debts owed to the municipality (in property tax, though the Council was not able to say how much exactly was owed), and inadequate/unpaid funding from the central government. Given that the average income per household was approximately MK53,900 or $76 \$$ USD per month (at the rate of 1 \$USD = MK707), the opportunity for the Council to increase taxes was limited.

Stakeholders expressed a clear demand for improved sanitation services and were receptive to new ideas: there were a variety of community groups and $\mathrm{CBO}$ s that already existed, community champions who were respected, and newly elected leaders who seemed committed. Furthermore, some organizations such as Plan Malawi had success working with community members and were able to reduce open defecation practices. The potential for violence and/or vandalism was an anticipated threat with respect to construction of new sanitation infrastructure but was considered minor.

The enabling environment assessment clearly illustrated some barriers (most prominently a lack of funding), but also pointed to a functioning civil society, an un-enforced, but unrestricted set of policies, and a stable, and clearly structured local government. The decision was made to continue the process despite an imperfect set of conditions.

\section{Step 3}

A total of 280 households across all 8 wards of the municipality were recruited in the household survey while 58 public water points were mapped. Findings from the survey are displayed in Table 1.

\section{Water}

More than $50 \%$ of the households in Luchenza identified public boreholes as their main drinking water supply and most users paid for water, i.e., an average of MK210/month for public borehole users, MK8,935/month for piped water to plot users, MK780/month for public tap users, and MK743/month for kiosk users ( $\$$ USD $=$ approximately $0.3,12,1$, and 1 , respectively). Water fetching took an average of $20 \mathrm{~min}$ for borehore users, $20 \mathrm{~min}$ for surface water users, $8 \mathrm{~min}$ for public tap users, and 7 min for kiosk users. However, the time values reported are based on traveling time only and not on queuing time. Only 5\% of the 149 households in Luchenza that used non-piped water practiced water purification at their household, i.e., by chlorination ( 5 households) and boiling (2 households).

A total of 58 public water points (boreholes, kiosks, and communal taps) were discovered (Figure 5), of which 45 were functional. The water tests revealed the complete absence $E$. coli and Total Coliforms. However, these samples were only taken at one point in time and not continuously throughout the various seasons which may affect contamination levels.

\section{Graywater and stormwater}

Graywater is any water from the household that is not from the toilet (i.e., shower, sink, etc.); $52 \%$ of the households disposed their graywater on the open ground. During the household 
TABLE 1 | Selected* environmental indicators across wards.

\begin{tabular}{|c|c|c|c|c|c|c|c|c|c|}
\hline \multicolumn{2}{|l|}{ Ward } & Kapiri & Lolo & Luchenza & Mapanga & Namadzi & Namisonga & Sambagalu & Thundu \\
\hline \multicolumn{2}{|l|}{ Sample $(n)$} & 35 & 35 & 36 & 35 & 35 & 35 & 35 & 35 \\
\hline \multirow[t]{2}{*}{ House ownership } & Own (\%) & 94 & 46 & 14 & 51 & 91 & 86 & 60 & 31 \\
\hline & Rented (\%) & 6 & 54 & 36 & 43 & 9 & 14 & 40 & 54 \\
\hline \multicolumn{2}{|c|}{ Household members (average \#) } & 5 & 5 & 6 & 4 & 5 & 5 & 5 & 5 \\
\hline \multicolumn{2}{|c|}{ Total household earning (MK) } & 40,774 & 62,703 & 62,454 & 65,133 & 55,359 & 35,365 & 43,935 & 67,384 \\
\hline \multicolumn{10}{|c|}{ Main water source (\%) } \\
\hline & Piped water to yard/plot & 17 & 43 & 69 & 46 & 20 & 23 & 57 & 54 \\
\hline & Public borehole & 77 & 29 & 31 & 49 & 77 & 74 & 37 & 0 \\
\hline & Water kiosk & 6 & 29 & 0 & 3 & 0 & 0 & 3 & 0 \\
\hline Pay for water (\% y & & 23 & 77 & 97 & 57 & 71 & 94 & 97 & 97 \\
\hline \multicolumn{10}{|c|}{ Graywater disposal method (\%) } \\
\hline & Open ground & 77 & 57 & 22 & 60 & 60 & 54 & 49 & 34 \\
\hline & Septic tank connected to a toilet & 0 & 11 & 28 & 6 & 3 & 9 & 3 & 31 \\
\hline & Other & 6 & 14 & 8 & 23 & 17 & 11 & 20 & 9 \\
\hline Standing water pre & (es) & 69 & 71 & 47 & 77 & 80 & 77 & 60 & 74 \\
\hline \multicolumn{10}{|c|}{ Type of sanitary facility (\%) } \\
\hline & Concrete slab and pit & 26 & 31 & 28 & 54 & 9 & 34 & 43 & 54 \\
\hline & Flush toilet and septic tank & 0 & 6 & 17 & 0 & 0 & 6 & 0 & 11 \\
\hline & Pour flush toilet and septic tank & 0 & 0 & 6 & 0 & 0 & 0 & 0 & 3 \\
\hline & Soil and sticks slab and pit & 66 & 37 & 11 & 34 & 83 & 51 & 49 & 9 \\
\hline Shared sanitary fac & & 20 & 20 & 31 & 43 & 51 & 37 & 17 & 46 \\
\hline \multicolumn{10}{|c|}{ Solid waste storage (\%) } \\
\hline & Containers (plastic/metal) & 0 & 20 & 14 & 6 & 0 & 0 & 9 & 54 \\
\hline & No storage (direct disposal) & 100 & 80 & 86 & 94 & 100 & 100 & 91 & 46 \\
\hline
\end{tabular}

*Not all options for each variable are presented and therefore not all variables total to 100\%; full results are presented in the Supplementary Material.

survey, we observed that $69 \%$ of the households had standing water present on their plot. Municipal drains were blocked with sand, stones, and solid waste which prevented stormwater from flowing freely which may encourage the growth of malaria transmitting mosquitos and other vectors.

Rainwater harvesting was reported by $71 \%$ of the households although most households collected the rain water directly from iron sheets and not through a rain water gutter. In addition, most households (29\%) reported that it was only a "little" rain water that could replace regular water supply. Flooding was experienced in $9 \%$ of the households.

\section{Sanitation}

Most households (96\%) across all wards had sanitary facilities on their plot. However, 34\% of these households reported sharing their sanitary facility(s) with other households, which is not considered as safely managed sanitation (World Health Organization and UNICEF, 2017). Although most houses had sanitary facilities, the most common toilet design was "unimproved" i.e., mud and stick designs with no vent pipes as observed in $44 \%$ of the households.

Pit emptying was not a common practice: filled latrines were replaced by new ones. On average, 64\% of the households had abandoned sanitary facilities on their plot and the average number of abandoned sanitary facilities per plot was 2 . Furthermore, there were no private pit emptiers in Luchenza.
The vacuum truck at the council was not in use due to a mechanical issue, but when it was in operation, it dumped sludge at the same dumpsite where the trash was disposed. The inability to empty pits or treat fecal sludge on-site for reuse or disposal means that pits have a higher likelihood of overflowing, causing people to practice open defecation, or emptying the fecal sludge themselves, all of which result in serious human and environmental health risks (Tayler, 2018).

There are 13 public toilets in Luchenza: 4 were built by the Council and cost MK50/use; 3 were built by the community and are free; 1 was built by a local MP and is free; and 4 are privately run and cost MK/use. Three of the 4 toilets built by the council are non-operational, but the privately run facilities are functional, and generally well-maintained.

The sites where community members mostly identified as potential sites for new public toilets in Luchenza were Chonde market, Luchenza market, Luchenza depot, and Luchenza hall.

\section{Solid waste}

Direct disposal of solid waste, i.e., disposing it onsite or wherever it was created, but not in a contained pit, was reported in $87 \%$ of the households. Composting was reported in $41 \%$ of the households across all wards. However, the type of composting that was practiced was "uncontrolled" where organics would be thrown in pits and after some time, applied in fields (i.e., without controlled thermophilic conditions or aeration). 


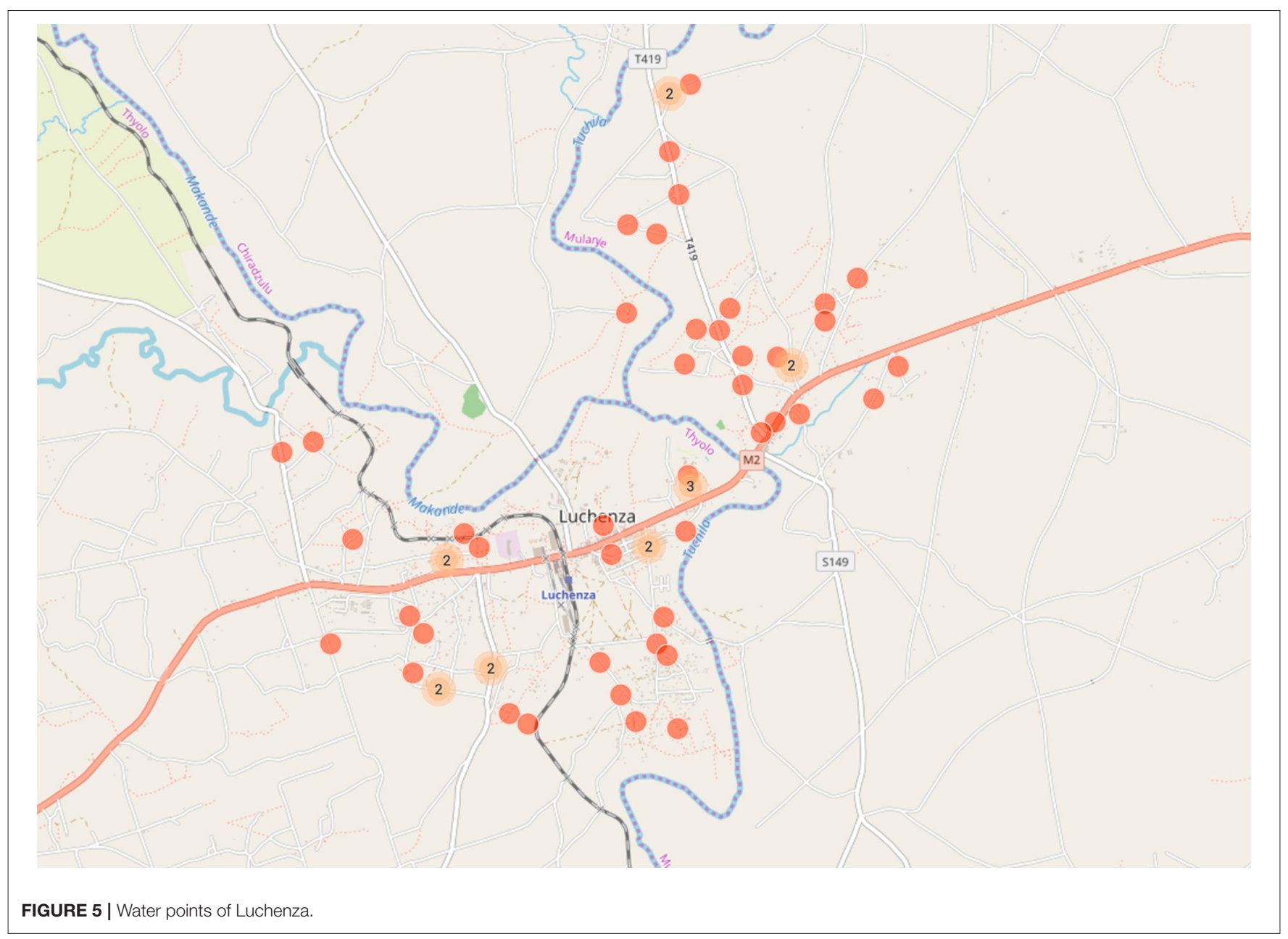

There was no waste collection truck in Luchenza. A pick-up truck would sometimes be hired for waste collection, but only for municipal solid waste i.e., in markets and in the trading center, but not household waste.

\section{Step 4}

Sixty people attended in the validation workshop, including the mayor and various councilors. The goal of the validation workshop was to have participants validate the results from Step 3 and/or provide corrections, and help to prioritize the problems that were identified. All results presented from the data collection exercise were validated by the community, though refuted by the representative from the Water Board. Through a pocket voting exercise, stakeholders identified water supply as a priority problem in Luchenza especially a shortage of public water points and frequent water outages for piped water. Fortythree percent of the households reported they had water outages of at least 1 day per week and $22 \%$ of households reported they had experienced water outages for up to a whole week. Stakeholders at the workshop in Luchenza also reported that they felt they were overcharged for piped water to their plot and that they were getting incorrect bills. Issues related to fecal sludge management and solid waste did not demand as much conversation or attention as those related to water, which became especially heated.

\section{Steps 5 and 6}

At planning stages 5 and 6 , we developed an environmental sanitation action plan: a guiding document that presents a comprehensive set of steps and recommendations for Luchenza. The contents of the sanitation plan were suggested and validated by the community in Luchenza through a workshop. The action plan addressed all components of environmental sanitation i.e., drinking water, gray- and stormwater, sanitation, fecal sludge, and solid waste, which the community members (both the municipal council and individual households) could adopt to meet their own stated objectives. The plan has short (1 year) and long-term activities, with a maximum number of 8 years. Furthermore, each target has specific roles for community members and the council (secretariat) with approximate costs.

During a third workshop, the researchers also grouped the 79 participants in 8 groups according to their location, i.e., 8 wards of the municipality. Each group had $\sim 10$ members: the ward councilor, ward chiefs, ward committee representatives, neighborhood committee representatives, community members representatives, and some staff from the municipal council and 
the water board. The aim of having these working groups was to have a community task force to initiate the action plan i.e., through advocacy and community activities. These working groups would also serve as support systems for the communities in implementing the action plan at household level. The groups identified stated their willingness to participate and agreed to meet in their wards to make a plan for implementing the strategy. The Action Plan is provided in the Supplementary Material.

\section{Step 7}

"Implementation of the Action Plan" should normally be completed by following the strategic plan that was developed and agreed upon in Step 6. However, because the City was unwilling to allocate any funds or time to implementation (and had refused to believe that we would not fund the implementation), we decided on a middle ground: to retrofit a model household with the most crucial facilities recommended in the environmental sanitation action plan. This was not required, or even mentioned in the CLUES guidelines, however we felt compelled to find a way to demonstrate some type of tangible outcome, both to "complete" the process and to appease the council. The aim of the model household was to serve as a reference point for other households, such that they could view the various technologies, learn how they operate and eventually, install some or all of them at their own home. The idea was for the model household to be open to visitors, and available to give technical guidance on how to construct or operate the identified technologies, having been trained by the project team. The model household would also have free brochures to give to the ward committees and/or individuals seeking technical guidance.

The model household was identified during the third workshop where the action plan was validated. The terms for selecting the model household were: willingness to serve as the model household, open to queries and ready to give technical guidance on how to set up the facilities, permanent residency in Luchenza, living on a plot that is not rented, sufficient land on the plot, and easy accessibility. To identify the model household, each of the 8 community working groups formed at the workshop nominated one participant and wrote down the name of the nominee on a piece of paper. The 8 pieces of paper containing names were folded and the project team anonymously picked the name. Very strict protocols like this were always necessary to guarantee transparency and negate any potential for accusations of favoritism.

The model household was equipped with a rain water gutter to harvest rain water, a soak pit and an interceptor tank to drain waste water from the household's cattle enclosure (biggest source of wastewater at the household), a hygienic dishwashing and laundry station, a Fossa Alterna sanitary facility, a hand washing station, a $4 \mathrm{~m}^{2}$ compost enclosure (made of bamboo) for organic waste, a garbage pit for inorganic waste, and an improved drain connection from the shower room to allow greywater to flow into a soak pit. Work at the model household was done by a contractor from Luchenza. Nevertheless, costs of the model household as depicted in Table 2 could be significantly reduced with the use of substitute materials such as grass or bamboo instead of bricks and iron sheets. The labor charge could also be removed or reduced
TABLE 2 | Model household expenses (exchange rates were calculated for the month of purchase).

\begin{tabular}{|c|c|c|c|}
\hline Facility & Cost & Amount (MK) & Amount (USD) \\
\hline \multirow[t]{3}{*}{ Soak pit } & Materials & 80,300 & 111 \\
\hline & Labor & 30,000 & 42 \\
\hline & Total & 110,300 & 153 \\
\hline \multirow[t]{3}{*}{ Rain water gutter } & Materials & 11,200 & 15 \\
\hline & Labor & 4,000 & 6 \\
\hline & Total & 15,200 & 21 \\
\hline \multirow{3}{*}{$\begin{array}{l}\text { Dishwashing and laundry } \\
\text { station }\end{array}$} & Materials & 24,800 & 34 \\
\hline & Labor & 15,000 & 21 \\
\hline & Total & 39,800 & 55 \\
\hline \multirow[t]{3}{*}{ Fossa Alterna } & Materials & 74,900 & 103 \\
\hline & Labor & 45,000 & 62 \\
\hline & Total & 119,900 & 165 \\
\hline \multirow[t]{3}{*}{ Handwashing station } & Materials & 2,800 & 4 \\
\hline & Labor & NA & NA \\
\hline & Total & 2,800 & 4 \\
\hline \multirow[t]{3}{*}{ Compost pile } & Materials & 8,000 & 11 \\
\hline & Labor & 7,500 & 10 \\
\hline & Total & 15,500 & 21 \\
\hline \multirow[t]{4}{*}{ Inorganics garbage pit } & Materials & 12,750 & 8 \\
\hline & Labor & 7,500 & 10 \\
\hline & Total & 20,250 & 18 \\
\hline & Grand total & 323,750 & 447 \\
\hline
\end{tabular}

as some of the work could be done by household members on their own.

Having completed the work at the model household, all the community working groups for the project were called for a tour, where the house owner (herself a Chief) explained what the facilities were and how they would be used. This event was to give insight and to motivate the groups on activities they could initiate in their own wards. A follow up at 1 month revealed that none of the group members had met; it was not clear if it was because the model household owner had prevented the groups from visiting or if the working groups had simply failed to attend. We were then prompted to organize a composting competition among the group members i.e., for them to motivate households in their wards to set up simple and basic compost piles $\left(1 \mathrm{~m}^{2}\right)$. Thinking that maybe the whole model household was too overwhelming or amibitious, the idea of the composting competition was to start with one component of the model household and build capacity step-wise. The group with the largest number of piles would receive a money prize (MK50,000 or $138 \$$ USD) followed by a runner up (MK50,000 or 70\$USD) but no ward could win without a minimum of 20 compost piles. After three more months of repeated follow-ups, only two groups (20 piles in Sambagalu ward and 15 piles in Kapiri ward) managed to make any compost piles. Furthermore, it was only one person in Sambagalu implementing the entire initiative (i.e., not the groups that had been formed). In Kapiri, the compost piles were mostly dry and clearly set up just for the judging. 
As a follow-up for the model household during a surprise inspection 4 months later, the household had inorganic waste all over the compound, the compost pile had been removed, the Fossa Alterna was very wet (i.e., dry organics/ash were not being added regularly), and a new bathroom had been constructed inside the house releasing graywater openly on the plot.

\section{Post-CLUES Meeting}

As a final stage for the project, we had the final meeting with representatives from the council and all ward councilors to report the findings. Though we attempted to highlight the positive results such as the updated data, increased awareness, early adoption of composting, etc., representatives from the council stressed that the implementation had "failed" due to a lack of "motivation" in monetary terms; specifically, they stated that the allowances given during the workshops were insufficient and that it would be hard for people to carry out the work in the working groups for free.

\section{CLUES Evaluation}

From the outset of this project, the goal was to evaluate the technical, political and financial feasibility of following the CLUES process in a Malawian small town. Our evaluation is based on our quantitative data, experiences, and critical reflections, especially those that occurred at the end of each step, as we re-read the instructions for the subsequent step and prepared to follow the guidelines, inevitably building upon what we had learned previously.

\section{Technical Feasibility}

Technical feasibility in this context, refers to how the easy the CLUES document was to use, and to how easy the steps were to implement.

\section{Availability and usability of recent data}

CLUES recommends a round of baseline data collection as one of the initial steps in the planning process: information on population and demography, stakeholders, recent maps, water and sanitation infrastructure (e.g., water points, public toilets), and physical characteristics (e.g., soil type, flooding). However, data availability was a challenge in Luchenza as most data were outdated. In some scenarios, the data were completely non-existent. In addition, Malawi suffers from frequent power outages. In Luchenza, the city council had its power disconnected due to unpaid bills and had to rely on a diesel generator, though because fuel is so expensive, they could only afford to use it for a few hours per day. As a result, digital data are rare (in Luchenza and across the country), and council staff continue to rely on paper-based information. There is no systematic data collection from the council which means that decisions are rarely, if ever made based on recent, robust information. In instances where data are available, it is usually stored away or in a disorganized pile of deteriorating papers that staff are unlikely to use.

As researchers, we had the time, money and motivation to collect necessary information (e.g., photocopying and enlarging maps at professional copiers), but it is unlikely that any application of the CLUES framework by a government body would have a similar luxury (i.e., large-scale copying was done in the major city, Blantyre).

\section{Time}

Although the CLUES framework does not specifically state the time required for each step, it recommends 18 months for the entire planning process.

The actual process took 22 months although it could have been shortened. One factor that led to the lengthy approach was the time spent collecting baseline data due to the low population density and the fact that some houses and areas were separated by features such as farms, rivers, and bushes (i.e., enumerators could not rapidly move between homes).

Secondly, the stakeholder analysis/identification was lengthy because of the lack of available information on existing stakeholders and poor coordination among stakeholders (stakeholders not knowing other stakeholders). Furthermore, obtaining consent/ approval from several bodies or individuals to conduct the study and/or execute some activities during the project delayed the planning process. For instance, permissions were requested from Thyolo DHO and the council to conduct the study, and also from Chonde Health Centre and Mulanje DHO to conduct water quality lab analyses at the health centre. Additionally, always notifying respective leaders (chiefs, councilors) before working in their area (i.e., during the household survey and mapping exercises) was a prerequisite which consumed a non-trivial amount of time. Though the "digital revolution" has purportedly come to Africa, official invitations must still be delivered on paper, by hand, for them to carry official status.

\section{Political Feasibility}

\section{Government support}

The geographical location of Luchenza played a significant role in how the government (both local and central) affected the planning process. As seen in Figure 2, Luchenza lies between two district councils (Thyolo and Mulanje) which creates confusion and overlap in management activities. Essentially, we were required to work with the two councils collaboratively e.g., when seeking permissions. When asking for permission to conduct the research (for ethical clearance), we were required to ask for permission from Thyolo District Health Office (DHO) but used one of the health centers in Luchenza for water quality tests, which required permission from the Mulanje DHO because the health center was situated on the "Mulanje side of Luchenza."

On a local government level, there was high staff turnover which affected institutional knowledge, acceptance and continuity. The high turnover was because Luchenza is viewed as a demotion for higher ranking government officials and is an "economic backwater" due to isolation, limited infrastructure and services e.g., electricity, and limited developmental (i.e., corruptable) projects (Caplan and Harvey, 2010). For instance, during the entire period the project was conducted i.e., 2 years, we worked with 3 different CEOs and 2 administrative officers. The high turnover means that there is limited ambition by the senior administration to invest in Luchenza because time spent by staff in Luchenza will be short and the returns, if any, would 
TABLE 3 | Cost estimate of CLUES steps in Luchenza (exchange rates were calculated for the month of purchase).

\begin{tabular}{|c|c|c|}
\hline Description & Amount (MK) & USD (\$) \\
\hline \multicolumn{3}{|c|}{ Steps 1 and 2-launching workshop and status assessment } \\
\hline \multicolumn{3}{|l|}{ A. Launching workshop } \\
\hline Purchase of mapping stickers & 4,550 & \\
\hline Venue booking & 20,000 & \\
\hline Venue toilet cleaning materials & 840 & \\
\hline Airtime & 12,500 & \\
\hline Assistant allowance & 5,000 & \\
\hline Catering (tea break and lunch) & 102,300 & \\
\hline Purchase of drinking water (80 bottles) & 30,560 & \\
\hline Purchase of 72 drinking bottles (incentives) & 65,400 & \\
\hline $\begin{array}{l}\text { Printing and photocopying invitation letters, } \\
\text { programs, and handouts }\end{array}$ & 8,050 & \\
\hline $\begin{array}{l}\text { Purchasing stationery (pens, pencils, A3 plain } \\
\text { papers) }\end{array}$ & 37,000 & \\
\hline Workshop tour transport & 41,000 & \\
\hline Planning transport & 17,800 & \\
\hline Transport allowance for 50 participants & 25,000 & \\
\hline Sub-total & 370,000 & 505 \\
\hline \multicolumn{3}{|l|}{ B. Status assessment } \\
\hline $\begin{array}{l}\text { Printing, photocopying and binding status } \\
\text { assessment reports }\end{array}$ & 16,840 & \\
\hline Sub-total & 16,840 & 23.16 \\
\hline Step total & 386,840 & 532 \\
\hline \multicolumn{3}{|c|}{$\begin{array}{l}\text { Step 3-detailed assessment (public water point mapping and } \\
\text { water testing, household survey) }\end{array}$} \\
\hline \multicolumn{3}{|l|}{ A. Public toilet mapping } \\
\hline Stationery & 8,020 & \\
\hline Airtime (other) & 5,900 & \\
\hline Airtime for hotspot internet & 6,500 & \\
\hline Transportation & 12,000 & \\
\hline Allowance for assistant for data collection & 50,000 & \\
\hline Sub-total & 82,420 & 113 \\
\hline \multicolumn{3}{|l|}{ B. Household survey } \\
\hline Airtime (other) & 19,450 & \\
\hline Airtime for hotspot internet & 47,100 & \\
\hline Transportation & 22,500 & \\
\hline Printing, photocopying, and purchasing stationery & 15,140 & \\
\hline Assistant allowance & 50,000 & \\
\hline Sub-total & 154,190 & 212 \\
\hline \multicolumn{3}{|l|}{ C. Water-point mapping } \\
\hline Airtime (other) & 2,200 & \\
\hline Transportation & 20,200 & \\
\hline Printing, photocopying, and purchasing stationery & 16,566 & \\
\hline Assistant allowance & 20,000 & \\
\hline Electrical supply/ appliances for lab & 7,650 & \\
\hline Lab security (windows, burglar bars) & 41,500 & \\
\hline Sub-total & 108,116 & 149 \\
\hline Step total & 344,726 & 474 \\
\hline \multicolumn{3}{|l|}{ Step 4- priorities workshop } \\
\hline Airtime (other) & 3,500 & \\
\hline Transportation & 4,000 & \\
\hline
\end{tabular}

(Continued)
TABLE 3 | Continued

\begin{tabular}{lcc}
\hline Description & Amount (MK) & USD (\$) \\
\hline Printing, photocopying, and purchasing stationery & 15,050 & \\
Venue & 20,000 & \\
Catering & 101,660 & \\
Assistant allowance & 3,000 & \\
Step total & 147,210 & \\
Step 5 and 6-action plan workshop & & \\
Airtime (other) & 4,000 & \\
Transportation & 12,500 & \\
Printing, photocopying, and purchasing stationery & 26,215 & \\
Venue & 20,000 & \\
Catering & 155,950 & \\
Assistant allowance & 13,000 & \\
Transport allowance for 75 participants & 75,000 & \\
Step total & 306,665 & \multirow{2}{*}{1,630} \\
\hline Grand Total & $1,185,441$ \\
\hline
\end{tabular}

likely go unnoticed by important officials. This scenario is likely true for most small towns across Malawi.

\section{Stakeholder participation}

The CLUES framework relies on stakeholder engagement and participation as an important factor throughout all planning steps. However, despite a constant presence, objective reinforcement, and city-backing, stakeholder participation was limited and a significant barrier to success. First, participants required financial motivations ("sitting fees") to attend workshops e.g., transportation allowances (on average MK1,000 per person) and other incentives e.g., food (on average, a meal cost K2,000 per person). Second, participants and council members required constant reminders and follow-ups in the form of telephone calls, printed invitations, and/or home visits. Third, over the course of hours of meetings and discussion, it became clear from the community representatives that any labor or contributions would be the responsibility of the city council, and that the community had only an advisory role. Privately and publicly in meetings, participants felt that if they contributed financially to any sort of infrastructure development, their money wouldn't be put to use (theft from officials). Similarly, some participants were of the general opinion that no matter what, environmental sanitation would not improve in Luchenza; a long history of failed promises and corruption [Malawi is the 120th least corrupt nation out of 175 assessed according to Transparency International (TI) (2019)] had left the community apathetic and doubtful of change.

\section{Institutional Arrangements/Responsibilities}

During the assessment of the enabling environment, it appeared as if there was a clear and defined administrative structure at the council. Furthermore, community working groups existed and were seemingly active: ward committees, Neighborhood Development Committees, Area Development Committees, and water point committees. Political leaders (councilors) and 
traditional leaders (chiefs) were also recognized in formal structures. However, the detailed assessment in Step 3 showed that there were no clearly defined responsibilities of the leaders or groups and the private sector was largely absent from localdecision-making processes. During the second workshop, some participants stressed that it was the duty of elected councilors to solve sanitation problems. Similarly, during the household survey, respondents stated that they were unwilling to raise funds for water points as it was not their duty to do so, but that of their leaders and the council secretariat.

\section{Expectations}

Despite numerous statements to the contrary, it is obvious that when the idea of CLUES was presented, individuals in Luchenza imagined that they would receive something, especially in monetary terms. Years of financial and material handouts to residents, along with a deeply embedded culture of government corruption seems to have prevented anyone from believing us when we continually emphasized that we were only helping to compile materials, facilitate discussions, and provide technical backstopping. Perhaps other projects had started in a similar fashion only to be coerced into extra investments by the end? Regardless of precedent, it was clear that no one's expectations were met.

\section{Financial Feasibility}

Even without researcher salaries, the CLUES process was expensive and not likely feasible for a small town in Malawi to afford on its own. A large portion of the cost went to incentives, catering, and transport allowances for participants, which may seem lavish but were, as discussed above, essential (Table 3). Workshops were useful in that they renewed enthusiasm, reminded the group about the progress and demonstrated the researchers' commitment (especially after the 1-year mark). However, commitments made by the Ward committees and the City Council to follow through on action items were rarely if ever achieved. Workshops were supposed to highlight and then build on the actions taken, but instead, we would accept the myriad of reasons why progress wasn't made and try to push on to the next step, conscious of the allotted timeline.

In terms of Luchenza's own solvency, they obtain minimal funding for WASH facilities and services from the central government and are supported by a small local tax base (Luchenza City Council, 2013). Table 4 displays the council's revenue source from 2008 to 2013. Assuming an annual income for our time period of $\$ 200,000$ (a higher than expected value given the trend), the process, excluding labor, transport, and overhead costs (e.g., internet) would represent about $1 \%$ of the budget. Considering that minimum wage in Malawi is MK $25,000 /$ month (33\$SD) and that the Council could rarely pay its electricity bill for the duration of the exercise, it is unlikely that this expenditure could or would be justified.

The "Other Recurrent Transactions" in Table 4 encompass Infrastructure Development Funds (IDF) and Sector Funds for Environment. We were unable to obtain official figures, but the city claims to have more than $40 \%$ of their tax bills outstanding. Currently, they issue letters and make visits to the offending citizens but do not have the power to freeze bank accounts, directly debit paychecks or take any other types of direct action.

\section{CONCLUSIONS AND RECOMMENDATIONS}

Our experience made clear that the CLUES process would likely not be feasible for a local council of a small town in Malawi to conduct. The lack of data, the time required, the financial investment, and the hierarchical culture that is founded on a long history of patronage and traditional chiefdoms, were not conducive to the long-term participatory process. However, Malawi is a special context in that it is exceptionally poor, has one of the lowest electrification rates in Africa, and a history of corruption that has been encouraged and exacerbated by the NGO culture of incentives or "sitting fees." That said, the CLUES process could, with modifications, be adapted and used with success in other countries or contexts.

The enabling environment must be thoroughly assessed prior to launching the project. As researchers, we had a research timeline so did not have the luxury of thoroughly evaluating the enabling environment before selecting Luchenza, and this was a mistake. As with many research projects, we had a fixed budget and deadline for deliverables. Doing a preliminary assessment of the enabling environment of multiple towns would have been the right thing but too time consuming for this study. Had we been adequately aware of the incentive expectation, the limited operating budget, the high turnover of government staff, and the general culture of apathy, we would not have initiated the process in Luchenza. Similarly, the lack of data, computers, maps, and documents cost us a great deal of time and money, and should have instead, signaled that the city was not ready or able to make use of evidence for decision-making.

In terms of the actual guidelines, the launching workshop mentioned in step 2 should be the kick-off event and/or the initial community meeting itself. Launching activities like sanitation marketing, where sanitation products and services would be showcased/sold, should be delayed until community members are more aware of sanitation issues and have a vocabulary and context in which to understand them. Furthermore, we as researchers did not have enough information about the project area before the assessment conducted in Step 3 to showcase or promote specific sanitation products or initiatives. We organized a demonstration trip to a composting facility for the participants to learn about the method and product, but, based on the observed and stated practices later on, the visit was too early and out of context for the participants to truly understand and embrace the technology for their own purposes.

Step 3 consumed the majority of the budget and must be shortened. Again, it would not have been so extensive had there been more available information. Specifically: sub-step 1 (collecting and synthesizing existing information about the 
TABLE 4 | Sources of revenue for Luchenza City Council (2013).

\begin{tabular}{|c|c|c|c|c|c|}
\hline Revenue source & 2008/09 USD (\$) & 2009/10 USD (\$) & 2010/11 USD (\$) & 2011/12 USD (\$) & 2012/13 USD (\$) \\
\hline Market fees & 25,931 & 23,401 & 35,755 & 50,621 & 27,409 \\
\hline Property rates & 22,330 & 57,211 & 66,551 & 99,838 & 48,558 \\
\hline Business licenses & 7,867 & 7,533 & 6,137 & 15,640 & $6,448.6$ \\
\hline Fees and other charges & 82,088 & 36,004 & 15,761 & 34,285 & 17,071 \\
\hline Other recurrent transactions (ORT) & 24,419 & 26,746 & 26,056 & 36,139 & 19306 \\
\hline Total & 162,636 & 150,894 & 150,260 & 236,525 & 118,792 \\
\hline
\end{tabular}

project area) should be part of the assessment of the enabling environment to determine if there is sufficient information, or sufficient willingness on the part of the host organization to collect and/or obtain it; otherwise, the process should probably be stopped. Data collection activities in this step should be done to supplement or update existing information, but not to generate completely new maps, accounting statements, and demographic surveys.

Finally, and most importantly, for the CLUES process to ever really succeed as a planning tool, it must be led/ implemented by an internal person or institution that is responsible for the project area. As researchers, we were interested in understanding how feasible the process would be so this necessarily biased the results, especially since there was an inherent assumption that minimal effort would be required from the council and that all costs would be covered. Any future use of CLUES should be done by experienced, full-time city planners who have contracts beyond the scope of the planning and implementation phase, to ensure commitment, buy-in and political will. External agencies who wish to support the use of CLUES should instead offer to fund the materials, data acquisition, experts, and other expenses required to complete the process, rather than actively leading it themselves.

The current CLUES document is 102 pages and users have access to 30 downloadable tools (e.g., example surveys, agendas, invitation letters, etc.). A simplified version (e.g., 30 pages) which specifies a few, concrete deliverables would make the document more useable and effective. In its current form the demands feel overwhelming and the process unwieldly. The goal of the guide should be to help users (a) identify what they have in terms of services, funding, and capacity; (b) determine what can be done given the resources available; and (c) prioritize the activities according to constraints.

In this and other contexts, the greatest benefit of using CLUES can come from the process of seeking out and compiling data, even if it is only to recognize that few data exist. Given that so little is known about small towns, concerted efforts should be made to help local governments collect, digitize and disseminate data for their own use, and if deemed feasible, future planning exercises.

\section{DATA AVAILABILITY STATEMENT}

All datasets generated for this study are included in the article/Supplementary Material.

\section{ETHICS STATEMENT}

The studies involving human participants were reviewed and approved by the National Health Sciences and Research Committee. Written consent was obtained from all households who participated in the household study.

\section{AUTHOR CONTRIBUTIONS}

WM managed the process and collected the primary field data. WM also participated in drafting the manuscript, analyzing the dataset, and writing the final manuscript. ET developed the research concept, supervised the field work, and collaborated on the writing and editing of the manuscript. All authors have read and approved the final manuscript.

\section{FUNDING}

Funding was provided by The Department of Sanitation, Water and Solid Waste for Development (Sandec) under the Swiss Federal Institute of Aquatic Science and Technology (Eawag).

\section{ACKNOWLEDGMENTS}

We thank Luchenza Municipal Council and all other sanitation stakeholders [councilors, chiefs, ward committees, neighborhood committees, Community Based Organizations (CBOs), water point committees, and market committees] in the municipality for dedicating their time to participate in the study. We thank Thyolo and Mulanje District Health Offices for granting us permission to conduct the study. Special recognition and thanks to Green Malata Children's Entrepreneurial Training Village for providing hands on training on sanitation technologies during workshops. We also thank Chonde Health Center for allowing us to use their laboratory for microbial water testing. Special thanks to the center for Water, Sanitation, Health and Technology Development (WASHTED) at the Malawi Polytechnic for providing intellectual and moral support. Lastly, we thank the Swiss Federal Institute of Aquatic Science and Technology (Eawag) for supporting this research.

\section{SUPPLEMENTARY MATERIAL}

The Supplementary Material for this article can be found online at: https://www.frontiersin.org/articles/10.3389/fenvs. 2019.00204/full\#supplementary-material 


\section{REFERENCES}

Awumbila, M. (2017). Drivers of Migration and Urbanization in Africa: Key Trends and Issues. New York, NY: Population Division Department of Economic and Social Affairs United Nations. Available online at: http://www.un.org/ en/development/desa/population/events/pdf/expert/27/papers/III/paperAwunbila-final.pdf

Caplan, K., and Harvey, E. (2010). Small Town Water and Sanitation Delivery. Taking a Wider View. London: WaterAid/Building Partnerships for Development (BPD). Available online at: http://www.bpdws.org/web/w/www 191_en.aspx

CWIS (2018). Citywide Inclusive Sanitation. Available online at: https:// citywideinclusivesanitation.com/

Humphreys, E., van der Kerk, A., and Fonseca, C. (2018). Public finance for water infrastructure development and its practical challenges for small towns. Water Policy 20, 100-111. doi: 10.2166/wp.2018.007

Hutton, G., and Varughese, M. (2016). The Costs of Meeting the 2030 Sustainable Development Goal Targets on Drinking Water, Sanitation, and Hygiene. Washington, DC: The World Bank. Available online at: http://www.worldbank. org/en/topic/water/publication/the- costs- of-meeting-the-2030-sustainabledevelopment- goal-targets-on-drinking-water-sanitation-and-hygiene

Ikwuyatum, G. O. (2016). Migration and urbanization: exploring the factors of the Nexus in Nigeria department of geography. Int. J. Human. Soc. Sci. 6, 161-175. Available online at: http://www.ijhssnet.com/journals/Vol_6_No_8_August_ 2016/17.pdf

Kvarnström, E., and McConville, J. (2007). "Sanitation planning-a tool to achieve sustainable sanitation," in Proceedings of the International Symposium on Water Supply and Sanitation For All. Available online at: http://www.sswm.info/sites/ default/files/reference_attachments/KVARNSTROEM and MCCONVILLE 2007 Sanitation planning A tool to achieve sustainable sanitation.pdf

Luchenza City Council (2013). Luchenza Municipal Council Urban Socio-Economic Profile. Luchenza: Luchenza Municipal Urban Council.

Lüthi, C., Morel, A., Tilley, E., and Ulrich, L. (2011). Community-Led Urban Environmental Sanitation Planning (CLUES). Duebendorf: Swiss Federal Institute of Aquatic Science and Technology.

Mugabi, J., and Njiru, C. (2005). "Maximizing the 'value' of improved water services in small towns," in Proceedings of the 31st WEDC International Conference (Kampala). Available online at: https://repository.lboro.ac.uk/ articles/Maximizing_the_value_of_improved_water_services_in_small_ towns/9589715/files/17228882.pdf

National Statistics Office (2019). 2018 Malawi Population and Housing Census: Main Report. Lilongwe: Government of Malawi.

Nguyen, M. T., Allemann, L., Ziemba, C., Larivé, O., Morgenroth, E., and Julian, T. R. (2017). Controlling bacterial pathogens in water for reuse: treatment technologies for water recirculation in the blue diversion autarky toilet. Front. Environ. Sci. 5:90. doi: 10.3389/fenvs.2017. 00090

OECD (2016). Malawi Profile. Available online at: https://www.oecd.org/regional/ regional-policy/profile-Malawi.pdf

Owusu, G. (2005). Small towns in Ghana: justifications for their promotion under Ghana’s decentralisation programme. Afr. Studies Quart. 8, 48-69. Available online at: http://asq.africa.ufl.edu/files/Owusu-Vol8Issue2.pdf

Peal, A. J., Evans, B. E., and van der Voorden, C. (2010). Hygiene and Sanitation Software: An Overview of Approaches. Geneva: Water Supply \& Sanitation Collaborative Council.
Richards, N., and Syallow, D. (2018). Water resources users associations in the Mara Basin, Kenya: pitfalls and opportunities for community based natural resources management. Front. Environ. Sci. 6:138. doi: $10.3389 /$ fenvs. 2018.00138

Roberts, B. H. (2014). Rural urbanization and the development of small and intermediate towns. Region. Dev. Dialog. 35, 1-23. Available online at: https:// www.researchgate.net/publication/311575572

Sandec-Eawag (2017). Sanitation Planning for Small Towns. Available online at: https://www.eawag.ch/fileadmin/Domain1/Abteilungen/sandec/ publikationen/SESP/Urban_Sanitation_general/sandec_policy5.pdf

Tayler, K. (2018). Faecal Sludge and Septage Treatment: A Guide for Low- and Middle-Income Countries. Rugby: Practical Action Publishing.

Thindwa, J. (2001). Enabling Environment for Civil Society in CDD Projects. Washington, DC: World Bank.

Thomas, A., and Alvestegui, A. (2015). Sanitation in Small Towns: Experience From Mozambique. UNICEF field note, 1-7. Available online at: https://www.unicef. org/esaro/WASH-Field-Small-Towns-low-res.pdf

Transparency International (TI) (2019). Malawi Corruption Rank. Available online at: https://radingeconomics.com/malawi/corruption-rank

Wafler, M. (2018). City Sanitation Plans (CSP). Available online at: https:// www.sswm.info/planning-and-programming/programming-and-planningframeworks/sanitation-frameworks-and-approaches/city-sanitation-plans$\% 28 \mathrm{csp} \% 29$ (accessed September 21, 2018).

Water Aid (2016). A Tale of Clean Cities: Insights for Planning Urban Sanitation from Ghana, India and the Philippines. London. Available online at: https:// washmatters.wateraid.org/publications/a-tale-of-clean-cities-insights-forplanning-urban-sanitation-from-ghana-india-and-the

Wessels, J. (2012). "Small towns: development potential or poverty traps? Making sure place doesn't take preference over people," in Strategies to Overcome Poverty \& Inequality "Towards Carnegie 111" (University of Cape Town). Available online at: https://www.mandelainitiative.org.za/images/docs/2012/ papers/293_Wessels_Small\%20towns\%20-\%20\%20development\%20potential \%20or\%20poverty\%20traps\%20-\%20making\%20sure\%20place\%20doesnt \%20take\%20preference\%20over\%20people.pdf

World Health Organization and UNICEF (2017). Progress on Drinking Water, Sanitation and Hygiene: 2017 Update and SDG Baselines. Geneva: World Health Organization (WHO) and the United Nations Children's Fund (UNICEF). Available online at: https://apps.who.int/iris/bitstream/handle/10665/258617/ 9789241512893-eng.pdf

Wright, A. (1997). Towards a Strategic Sanitation Approach. Improving the Sustainability of Urban Sanitation in Developing Countries, World Bank and UNDP Water and Sanitation Programme. Washington, DC. Available online at: https://www.wsp.org/sites/wsp/files/publications/global_ ssa.pdf

Conflict of Interest: The authors declare that the research was conducted in the absence of any commercial or financial relationships that could be construed as a potential conflict of interest.

Copyright (c) 2020 Mtika and Tilley. This is an open-access article distributed under the terms of the Creative Commons Attribution License (CC BY). The use, distribution or reproduction in other forums is permitted, provided the original author(s) and the copyright owner(s) are credited and that the original publication in this journal is cited, in accordance with accepted academic practice. No use, distribution or reproduction is permitted which does not comply with these terms. 